\title{
IMPLEMENTAÇÃO DE TECNOLOGIA TOUCHSCREEN NO ACESSO AOS SERVIÇOS DE COMPARTILHAMENTO DE BICICLETAS DO PROJETO BIKE ITAÚ
}

\section{IMPLEMENTATION OF TOUCHSCREEN TECHNOLOGY IN ACCESS TO BICYCLE SHARING SERVICES OF THE BIKE ITAÚ PROJECT}

\author{
Luciana Machado Antar ${ }^{1}$, BEng. \\ Ana Cristina Maurício Ferreira², MsC. \\ (1) Engenheira de Produção \\ e-mail: lucianaantar@gmail.com \\ (2) Universidade Estadual Paulista (UNESP), PPGDesign-FAAC \\ e-mail: anacr.fatec@gmail.com
}

Palavras chave: Mobilidade urbana sustentável, Compartilhamento de bicicletas, Projeto Bike Itaú.

\begin{abstract}
O compartilhamento de bicicletas dentro das sociedades modernas é uma das principais formas de mobilidade urbana sustentável, reduzindo os impactos negativos causados pelo excesso de transportes motorizados de combustão interna. Neste aspecto, o projeto Bike Itaú promove a socialização e a conscientização ecológica da bicicleta, apontada como transporte verde não poluente e de baixo custo econômico. O objetivo deste trabalho foi promover melhorias no serviço de compartilhamento do Bike Itaú, através da implementação da tecnologia touchscreen, para o desbloqueio das bicicletas. Na metodologia foram realizadas etapas de verificação do sistema atual, aplicação de pesquisa de satisfação junto aos usuários na cidade de Salvador/BA, análise de sistemas similares, definição de requisitos para o desenvolvimento da melhoria proposta e apresentação do modelo do sistema sugerido. Com a implementação do touchscreen como mais uma opção de desbloqueio, os usuários poderão ser beneficiados com as vantagens desta tecnologia no que diz respeito à facilidade de uso e à inclusão aos serviços de compartilhamento de bicicletas.
\end{abstract}

Keywords: Sustainable urban mobility, Bike sharing, Bike Itaú Project.

The sharing of bicycles within modern societies is one of the main forms of sustainable urban mobility, reducing the negative impacts caused by excess motorized internal combustion transports. In this regard, the Bike Itaú project promotes the socialization and ecological awareness of the bicycle, which is considered as a green transport that is not polluting and of low economic cost. The objective of this work was to promote improvements in the Itaú Bike sharing service, through the implementation of touchscreen technology, for the unblocking of bicycles. In the methodology were carried out verification steps of the current system, application of satisfaction survey with users in the city of Salvador/BA, analysis of similar systems, definition of requirements for the development of the proposed improvement and presentation of the suggested system model. With the touchscreen implementation as yet another unlock option, users will benefit from the benefits of this technology in terms of ease of use and inclusion in bike sharing services. 


\section{$16^{\circ}$ \\ ERGODESIGN USIHC CINAHPA}

\section{Introdução}

Mobilidade e sustentabilidade são temas de extrema relevância na atualidade. A preocupação com o meio ambiente e com o futuro dos recursos naturais, refletem na busca por soluções em materiais, tecnologias e meios de transportes. Nos centros urbanos devem ser considerados e incentivados modos de transporte que buscam a sustentabilidade, melhorando as condições de deslocamento e diminuindo os impactos ambientais negativos.

Dentre os diversos meios de transportes existentes, a bicicleta pode ser considerada um modo ecologicamente sustentável, pois reduz o tráfego nos percursos mais curtos e mais centrais, reduz o consumo energético, contribui para a diminuição da poluição e para a mínima produção de ruídos. Aos usuários, promove o condicionamento físico e mental, contribuindo assim para a melhora da saúde pública e da qualidade de vida.

Assim, é importante que o acesso às bicicletas disponíveis para compartilhamento seja otimizado, para alcançar o maior número de usuários, independentemente de seu nível socioeconômico, fazendo com que o serviço seja igualitário e viável a todos. Atualmente, as bicicletas do Bike Itaú tem como forma de desbloqueio as ligações telefônicas, o cartão de desbloqueio e o aplicativo para smartphones. Este último item apresenta como fator limitante a sua atualização, pois aparelhos que não tiverem sistemas operacionais iguais ou superiores ao Android 3.0, IOS 6.1 ou Windows Phone 8.0 e 8.1, não poderão baixar o aplicativo e utilizar o serviço por esse meio, limitando o desbloqueio das bicicletas apenas por ligação telefônica ou cartão (que nem todos os usuários possuem). Pode haver, desta forma, um novo problema, pois muitos usuários ficam sem créditos para realizar a ligação ou ocorrendo de ficar com a bateria descarregada. Neste contexto, o objetivo geral deste trabalho foi promover melhorias no serviço de compartilhamento de bicicletas do Bike Itaú, através da implementação da tecnologia touchscreen. O objetivo específico desta implementação é o fornecimento de um serviço que se faça de forma eficiente e intuitiva. $16^{\circ}$ Ergodesign - Congresso Internacional de Ergonomia e Usabilidade de Interfaces Humano Tecnológica: Produto, Informações Ambientes Construídos e Transporte

$16^{\circ}$ USIHC - Congresso Internacional de Ergonomia e Usabilidade de Interfaces Humano Computador

CINAHPA | 2017 - Congresso Internacional de Ambientes Hipermídia para Aprendizagem.

\section{Revisão bibliográfica}

\subsection{Compartilhamento de bicicletas - modo sustentável de mobilidade urbana}

Diversos são os aspectos relacionados à mobilidade que levam à degradação dos sistemas de circulação nas cidades brasileiras e à desumanização dos espaços urbanos, entre eles, destaca-se a cultura de deslocamento brasileira, onde predomina o uso intensivo do automóvel particular, gerando congestionamentos e impactos ambientais negativos (SILVEIRA, 2010). Os indivíduos tem, gradativamente, adquirido condições econômicas para terem seus veículos individuais, o que acarreta em uma sobrecarga na infraestrutura de trânsito dos municípios, assim como nas questões ambientais de emissão de poluentes e na qualidade de vida dos cidadãos, visto que aumenta em muito o tempo dos deslocamentos (CADENA et al, 2014). Os efeitos diretos e indiretos da predominância dos veículos automotores no trânsito envolvem problemas ambientais, de tráfego, de planejamento urbano e de qualidade de vida (FERREIRA, 2010).

É importante a percepção de que a mobilidade urbana sustentável não deve gerar segregação espacial, mas ser socialmente inclusiva e ecologicamente sustentável, devendo atender às necessidades da sociedade de se deslocar livremente, promovendo a qualidade de vida dos cidadãos desta e das futuras gerações e deve estar integrada às demais políticas urbanas (BRASIL, 2006). Neste contexto, a bicicleta é um meio eficiente de reorganizar a mobilidade e os espaços urbanos.

É valido criar estratégias de investimento para meios de transporte de baixa capacidade e complementares, ao meio urbano, proporcionando integração e formas opcionais de transporte. $\mathrm{O}$ uso da bicicleta, e seus sistemas de compartilhamento, necessitam de novas demandas, como forma de valorizar esse meio de transporte. São estas as razões para a análise de compartilhamento de bicicletas, os aparelhos disponíveis, as tecnologias, e o funcionamento destes organismos a serviço dos seus usuários, e quais são os recursos que 


\section{$16^{\circ}$ \\ ERGODESIGN USIHC CINAHPA}

possibilitam a ida e a vinda em suas viagens.

O compartilhamento de bicicletas surgiu em meados de 1960, na Holanda, moldando a vida das pessoas e o ambiente em que viviam. Atualmente, existem mais de 850 programas de compartilhamento de bicicletas no mundo (THE CITY FIX BRASIL, 2016). No Brasil, surgiu através do grupo Serttel, que iniciou o serviço em 2011, na cidade do Rio de Janeiro, tendo como patrocinador o banco Itaú, denominando o sistema como Projeto Bike Itaú. Além do Rio de Janeiro, a Serttel é responsável pelo sistema em diversas outras cidades brasileiras, como Belo Horizonte/MG, Brasília/DF, Salvador/BA, São Paulo/SP, entre outras. Além do banco Itaú, existem outros patrocinadores, sendo que o projeto funciona através de Termos de Concessões de Uso concedidos pela prefeitura de cada cidade à Serttel (FEIJÓ, 2015).

Os programas se expandiram rapidamente no país e, em 2013, em Pernambuco, teve início o primeiro sistema intermunicipal. Além dos benefícios já conhecidos referentes ao meio ambiente e à saúde e qualidade de vida dos cidadãos, a implantação dos programas de compartilhamento estimula os investimentos na infraestrutura cicloviária das cidades envolvidas (PEREIRA, 2014).

\subsection{Tecnologia touchscreen}

A tela touchscreen (sensível ao toque) é um display eletrônico visual que detecta a presença e a localização de um toque no visor do dispositivo, por meio de pressão feita com o dedo ou a mão (HAMMERSCHMIDT, 2008). Encontra-se presente em diversos tipos de serviços presentes no dia a dia dos cidadãos, como é o caso de terminais de atendimento ao público, caixas eletrônicos de bancos, smartphones e tablets, sendo que o uso crescente da internet em smartphones intensificou a utilização desta interface tecnológica.

As interfaces touchscreen permitem ao usuário a interação direta e rápida com as funcionalidades dispostas na tela, resultando em vantagem se comparada às outras interfaces. Nesta interface, todas as informações a serem acessadas e todos os $16^{\circ}$ Ergodesign - Congresso Internacional de Ergonomia e Usabilidade de Interfaces Humano Tecnológica: Produto, Informações Ambientes Construídos e Transporte

$16^{\circ}$ USIHC - Congresso Internacional de Ergonomia e Usabilidade de Interfaces Humano Computador

CINAHPA | 2017 - Congresso Internacional de Ambientes Hipermídia para Aprendizagem. movimentos necessários para o acesso às informações são centralizados em um único espaço, a tela do dispositivo (RHENIUS et al, 2015).

Conforme Barret e Omote (2010), as vantagens mais importantes das telas touchscreens são de possuírem capacidade de multitoques, durabilidade e excelente desempenho ótico de transmissão. Esses recursos visivelmente são cada vez mais satisfatórios dependendo de cada aparelho, ou dispositivo. Sua aplicabilidade é performática e cada vez mais evoluída, estando presente em diversos dispositivos e serviços utilizados nas atividades diárias.

As telas sensíveis ao toque dispensam o uso de periféricos como mouses ou teclados e tem interface interativa. Assim o usuário poderá selecionar uma função tocando em palavras, imagens ou outro elemento gráfico presente na tela. Além da questão da facilidade de uso, a existência da tela touchscreen nas estações pode oferecer mais segurança aos usuários quanto ao uso de smartphones, pois no Brasil já existe mais de cinco milhões de registros de roubo ou perda destes aparelhos (GOMES, 2015). A evolução tecnológica permite cada vez mais novas formas de organização de pensamentos e novas formas de interação homem/máquina.

\section{Procedimentos metodológicos}

\subsection{Verificação do processo atual de desbloqueio}

O processo de utilização do sistema tem início no acesso ao site do projeto, onde o sujeito efetua o cadastro, habilitando o seu credenciamento e se tornando um usuário, com login e senha. Quando o usuário necessita utilizar uma bicicleta, tem três formas diferentes de desbloqueio: por ligação telefônica, por aplicativo instalado em smartphone ou por cartão de desbloqueio. Por aplicativo ou por ligação de telefone, o usuário escolhe o número da estação e, na sequência, o número da bicicleta. Quando o uso é por cartão, não é realizada a escolha da estação, somente da bicicleta. Em seguida, a mesma é desbloqueada e retirada para o uso. 


\section{$16^{\circ}$ \\ ERGODESIGN USIHC CINAHPA}

\subsection{Pesquisa de satisfação}

Com o intuito de avaliar a satisfação dos usuários de bicicletas compartilhadas foi elaborada uma pesquisa com alguns elementos que envolvem o projeto, porém com foco principal na liberação das bicicletas. Trata-se de um estudo transversal com a participação de 15 sujeitos que fazem uso do compartilhamento de bicicletas na cidade de Salvador/BA, com a coleta dos dados na estação 04-Porto da Barra, escolhida aleatoriamente para a aplicação do questionário.

A pesquisa consistiu na aplicação de um questionário elaborado contendo catorze questões (de múltipla escolha e abertas) divididas conforme os resultados a seguir:

\subsubsection{Caracterização dos sujeitos e do uso das bicicletas}

Dos 15 sujeitos participantes da pesquisa, 10 são do gênero masculino e 5 do gênero feminino, com faixa etária predominante de 21 a 30 anos e com renda financeira na faixa de 1 a 4 salários mínimos. Quanto ao uso das bicicletas, os participantes tinham três opções a escolher (lazer, trabalho, estudo ou outras), sendo que $100 \%$ deles declararam utilizar para fins de lazer e mais trabalho ou estudo, com a frequência de uso, em sua maioria, de duas a três vezes na semana.

\subsubsection{Sobre o uso do smartphone}

Sobre o uso de smartphone (possui o aplicativo em seu celular?), $66,7 \%$ dos entrevistados declararam possuir o aplicativo para celular e acessarem o sistema através dele. Diversos entrevistados declararam conhecer pessoas que deixaram de utilizar o compartilhamento por não possuírem aparelhos de celular com sistemas operacionais iguais ou superiores ao Android 3.0, ao IOS $6.1 \mathrm{ou}$ ao Windows Phone 8.0 e 8.1 que suportam a atual versão do aplicativo.

\subsubsection{Sobre insatisfações em relação ao serviço}

Quanto à insatisfação em relação ao serviço, $46,7 \%$ dos entrevistados disseram ter insatisfações com o sistema, sendo as principais reclamações $16^{\circ}$ Ergodesign - Congresso Internacional de Ergonomia e Usabilidade de Interfaces Humano Tecnológica: Produto, Informações Ambientes Construídos e Transporte

$16^{\circ}$ USIHC - Congresso Internacional de Ergonomia e Usabilidade de Interfaces Humano Computador

CINAHPA | 2017 - Congresso Internacional de Ambientes Hipermídia para Aprendizagem.

referentes à manutenção, à internet que frequentemente fica fora do ar e ao fato de muitas vezes não conseguirem liberar as bicicletas por ligações telefônicas. $26,7 \%$ dos entrevistados disseram apresentar algum tipo de dificuldade no uso do sistema, sendo que estas dificuldades ocorrem no momento da liberação das bicicletas.

\subsubsection{Quanto ao sistema atual de liberação}

Quanto ao sistema atual de liberação, à possibilidade de haver uma nova forma de liberação que não obrigue o usuário a fazer uso de um aparelho telefônico ou o cartão SalvadorCard e ao fato de não existir o aplicativo Bike Salvador para celulares mais antigos, as alternativas de respostas predominantes foram regular, ótimo e péssimo, respectivamente.

\subsubsection{Sugestões a respeito da liberação}

Destacam-se, entre outras, as sugestões feitas pelos participantes da pesquisa a respeito da liberação das bicicletas nas estações, sendo a existência de um código de acesso para cada usuário, o acesso por cartão de crédito como alternativa e a existência de alguma forma de acesso que não necessite de aparelho telefônico ou cartão de desbloqueio.

\subsection{Análise comparativa de sistemas similares}

No desenvolvimento de projetos de produtos, analisar e comparar sistemas similares é importante para conhecer pontos fracos e identificar possíveis pontos de melhoria que possam oferecer vantagens competitivas. Baxter (2005) esclarece que esta análise deve descrever os produtos similares de modo a verificar quais características o novo produto pode possuir para satisfazer as necessidades dos usuários, quais as oportunidades tecnológicas de inovação e, assim, definir a nova proposta de projeto.

Neste estudo, a análise de similares teve, basicamente, a função de comparar os principais atributos dos serviços de compartilhamento existentes nas cidades de Salvador/Brasil (BIKE SALVADOR, 2016), Paris/França (VÉLIB, 2016), Nova York/Estados Unidos (CITIBIKE, 2016), 


\section{$16^{\circ}$ \\ ERGODESIGN USIHC CINAHPA}

Buenos Aires/Argentina (BA ECOBICI, 2016) e Melbourne/Austrália (MELBOURNE BIKE SHARE, 2016). Os atributos comparados foram existência de lâmpadas de sinalização no momento de liberação ou bloqueio da bicicleta, possibilidade de realização de cadastro online, desbloqueio das bicicletas com utilização de celular (aplicativo de celular), desbloqueio das bicicletas com utilização de celular (ligação), desbloqueio por cartão, sistema de consulta de disponibilidade online por aplicativo no celular, tecnologia touchscreen para acesso aos serviços, chave e código de liberação.

O Vélib (França) é um serviço de compartilhamento que possui lâmpadas indicativas de liberação, aplicativo para a visualização das estações, o cadastro pode ser feito online ou diretamente na tela touchscreen presente na estação e atende clientes diários ou anuais. Para os clientes diários, o pagamento é feito na própria estação, sendo liberado um bilhete de desbloqueio que o aparelho fornece impresso. Para a liberação da bicicleta, o usuário digita os números contidos no bilhete. Aos clientes anuais, além do procedimento normal, é fornecida uma chave de liberação, dispensando o uso da tela na estação (VÉLIB, 2016).

O sistema Melbourne Bike Share (Austrália) possui lâmpadas de sinalização de bloqueio/desbloqueio, liberação por aplicativo ou cartão. Todo o procedimento pode ser feito na tela touchscreen e o aparelho libera um bilhete que deve ser inserido na própria bicicleta para a liberação e depois guardado. Clientes fixos recebem uma chave de segurança, sendo que a bicicleta só é liberada com esta chave (MELBOURNE BIKE SHARE, 2016).

O Citibike NYC (Estados Unidos) permite cadastramento e desbloqueio por aplicativo (que também mostra as estações da cidade), gerando um código que deve ser digitado na estação para liberação da bicicleta. Possui chave de segurança para a liberação, dispensando, neste caso, o uso do celular. Todo o procedimento também pode ser feito na tela touchscreen existente na estação, porém um bilhete (que deve ser guardado) é emitido para ser inserido na bicicleta que será $16^{\circ}$ Ergodesign - Congresso Internacional de Ergonomia e Usabilidade de Interfaces Humano Tecnológica: Produto, Informações Ambientes Construídos e Transporte

$16^{\circ}$ USIHC - Congresso Internacional de Ergonomia e Usabilidade de Interfaces Humano Computador

CINAHPA | 2017 - Congresso Internacional de Ambientes Hipermídia para Aprendizagem. utilizada (CITIBIKE, 2016).

Os sistemas Bike Itaú (Brasil) e BA Ecobici (Argentina) possuem todos os atributos em comum, como a existência de lâmpadas de sinalização, o cadastramento online, as três formas de desbloqueio (aplicativo, ligação telefônica e cartão de desbloqueio), assim como a consulta online de disponibilidade. Ambos os sistemas não possuem a tecnologia touchscreen em suas estações de compartilhamento.

Com a análise dos principais atributos existentes (Quadro 1) foi possível observar que os sistemas apresentam características comuns a todos, como a sinalização de desbloqueio por lâmpadas, cadastro online, desbloqueio por cartão e consulta de disponibilidade pelo aplicativo do smartphone. Os atributos que não são comuns aos cinco sistemas analisados são o desbloqueio por aplicativo e ligação telefônica e chave/código de liberação. As estações que possuem a tela touchscreen fazem uso da mesma para o acesso aos serviços, porém para a liberação das bicicletas são associados códigos ou bilhetes.

Quadro 1 - Análise comparativa de similares

\begin{tabular}{|l|l|l|l|l|l|}
\hline \multirow{2}{*}{ Atributos } & \multicolumn{3}{|c|}{$\begin{array}{c}\text { Serviços de } \\
\text { compartilhamento }\end{array}$} \\
\hline & 1 & 2 & 3 & 4 & 5 \\
\hline $\begin{array}{l}\text { Lâmpadas de sinalização do } \\
\text { bloqueio/desbloqueio }\end{array}$ & & & & & \\
\hline Cadastro online & & & & & \\
\hline Desbloqueio usando o smartphone & & & & \\
\hline $\begin{array}{l}\text { Desbloqueio usando ligação } \\
\text { telefônica }\end{array}$ & & & \\
\hline Desbloqueio usando cartão & & & & \\
\hline Consulta de disponibilidade online & & & & \\
\hline $\begin{array}{l}\text { Tecnologia touchscreen para } \\
\text { acesso aos serviços }\end{array}$ & & & \\
\hline Chave de liberação & & \\
\hline Código de liberação & \\
\hline Legenda: & & \\
\hline 1 & Bike Itaú (Brasil) \\
\hline 2 & Vélib (França) \\
\hline $3 \quad$ Citibike NYC (Estados Unidos) \\
\hline $4 \quad$ BA Ecobici (Argentina) \\
\hline $5 \quad$ Melbourne Bike Share (Austrália) \\
\hline
\end{tabular}

Realização:

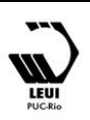




\section{$16^{\circ}$ \\ ERGODESIGN USIHC CINAHPA}

\subsection{Requisitos do projeto}

Nesta etapa foram definidas especificações e necessidades básicas ao desenvolvimento e implementação do novo sistema de desbloqueio de bicicletas, os requisitos que, conforme o Guia do Conhecimento e Gerenciamento de Projetos (PMBOK, 2000), "são condições ou capacidades que devem ser supridas pelo produto, serviço, ou resultado do projeto, para satisfazer a um contrato, padrão, especificação ou outro documento formal". Os requisitos foram formulados a partir dos dados primários obtidos na pesquisa de satisfação e dos dados secundários obtidos na análise de sistemas similares (Quadro 2).

Quadro 2 - Requisitos do projeto

Características importantes no desenvolvimento do projeto

Possibilitar a liberação sem ligação telefônica

Possibilitar a liberação sem cartões

Possibilitar a liberação sem aplicativos em smartphones

Ter interface de fácil acesso e compreensão

Ter interface de uso intuitivo

Utilizar a interface touchscreen para acesso e liberação, sem uso adicional de chave ou impressão de bilhete

\section{Resultados}

A tecnologia touchscreen é utilizada através da instalação de uma tela sensível ao toque no corpo das estações, como pode ser visto na figura 1.

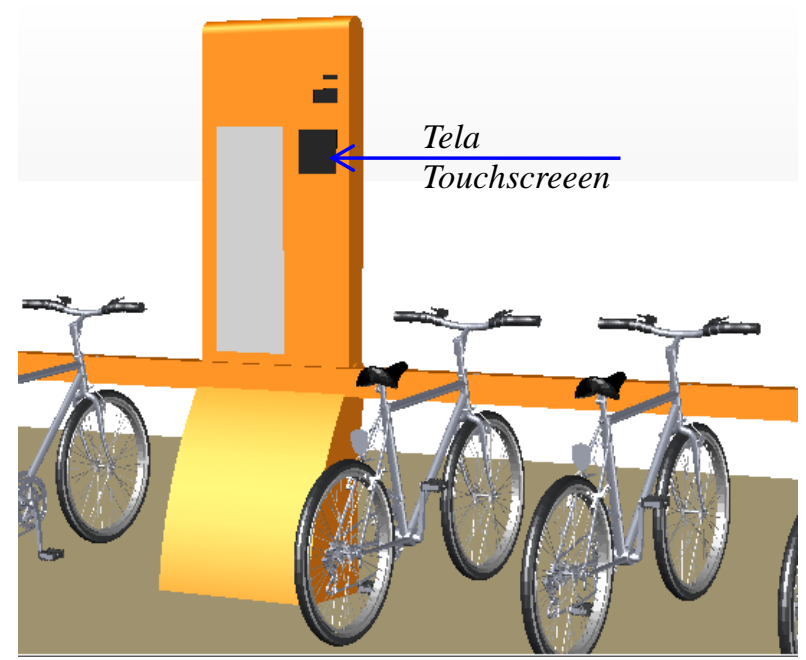

Figura 1 - Estação de compartilhamento com a tela touchscreen $16^{\circ}$ Ergodesign - Congresso Internacional de Ergonomia e Usabilidade de Interfaces Humano Tecnológica: Produto, Informações Ambientes Construídos e Transporte

$16^{\circ}$ USIHC - Congresso Internacional de Ergonomia e Usabilidade de Interfaces Humano Computador

CINAHPA | 2017 - Congresso Internacional de Ambientes Hipermídia para Aprendizagem.

A nova proposta apresenta mais uma opção de desbloqueio das bicicletas, através da tecnologia touchscreen, com o processo completo representado no fluxograma da Figura 2.

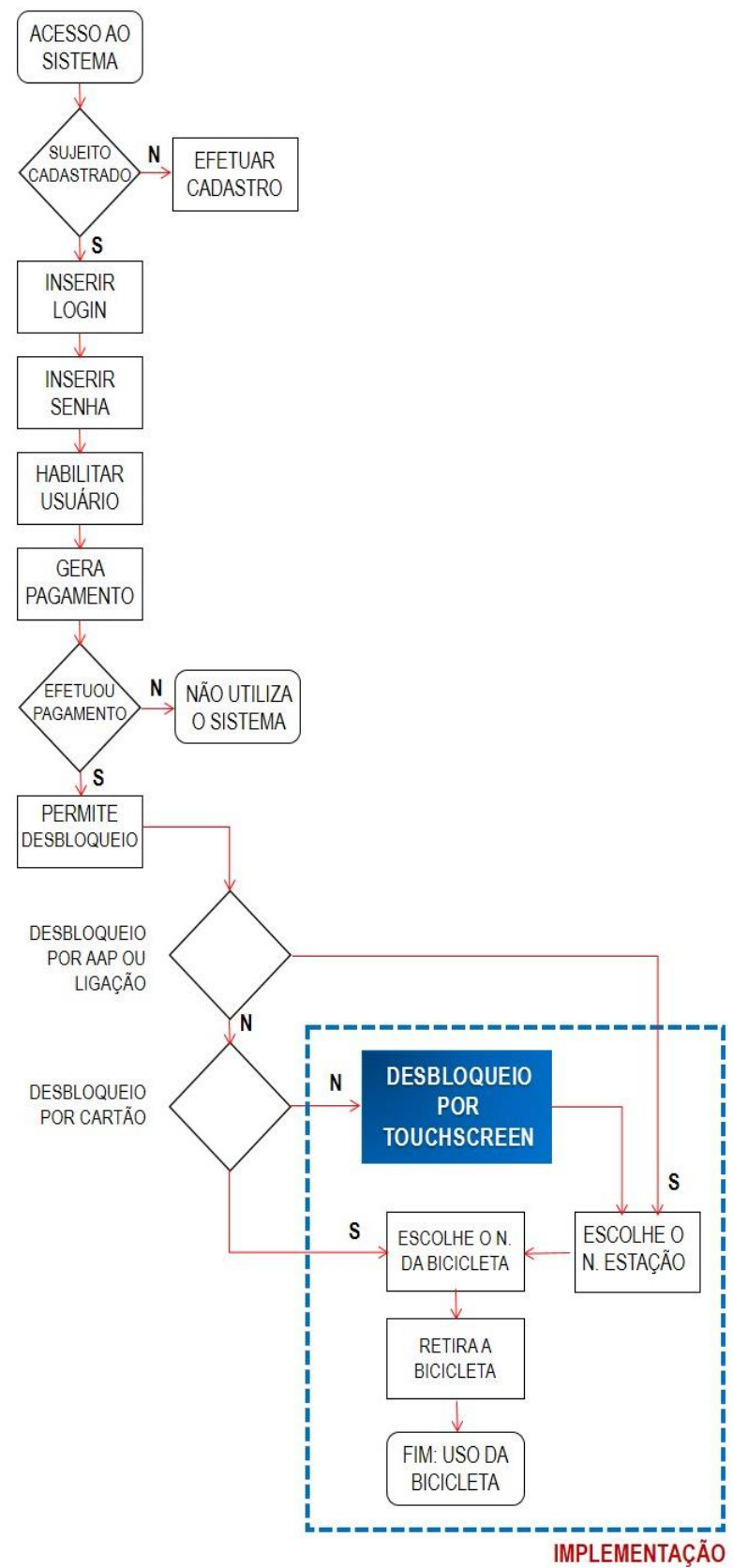

Figura 2 - Fluxograma do sistema proposto

O procedimento de uso de bicicletas compartilhadas já com a implementação sugerida, ou seja, com o uso da tecnologia touchscreen
Realização:

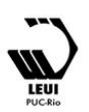




\section{$16^{\circ}$ \\ ERGODESIGN USIHC CINAHPA}

ocorre diretamente na estação dispensando o uso de smartphones ou cartões. O processo, basicamente, consiste no acesso do usuário à estação de compartilhamento, onde o mesmo vai tocar a tela touchscreen para ligá-la. Após o toque, o usuário, previamente cadastrado, insere login e senha, recebendo a confirmação da habilitação do usuário. Após aparecer na tela a confirmação da habilitação, o usuário deve validar a estação em que se encontra, selecionar uma das bicicletas disponíveis, confirmar a intenção de liberação e aguardar a sinalização indicativa de desbloqueio através das lâmpadas de sinalização. Na sequência o sistema desbloqueia a bicicleta selecionada, o usuário a retira e o sistema é finalizado (Figura 3).
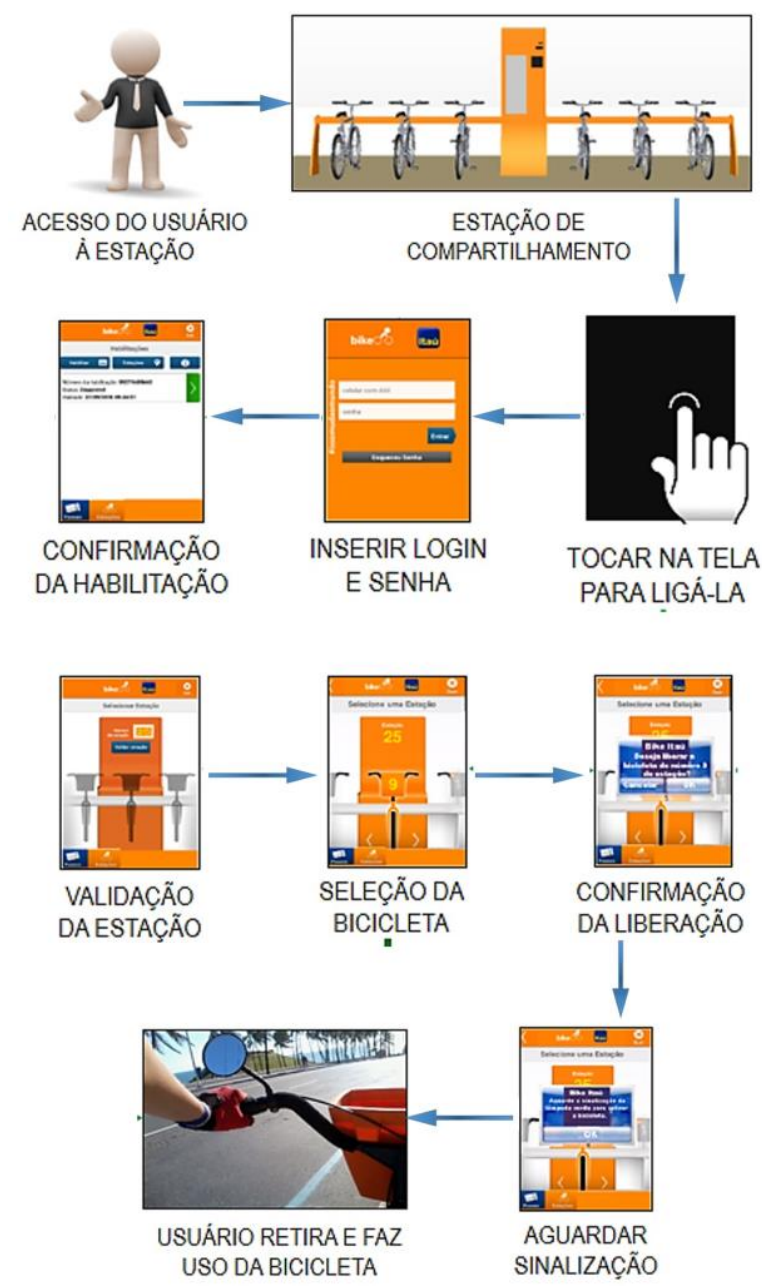

Figura 3 - Fluxograma sequencial de acesso e liberação das bicicletas por meio do método proposto. $16^{\circ}$ Ergodesign - Congresso Internacional de Ergonomia e Usabilidade de Interfaces Humano Tecnológica: Produto, Informações Ambientes Construídos e Transporte

$16^{\circ}$ USIHC - Congresso Internacional de Ergonomia e Usabilidade de Interfaces Humano Computador

CINAHPA | 2017 - Congresso Internacional de Ambientes Hipermídia para Aprendizagem.

\section{Conclusão}

Em face aos diversos fatores que envolvem uma sociedade moderna, aspectos como sustentabilidade, mobilidade, inclusão social e tecnologia são importantes de serem abordados e considerados em estudos científicos e acadêmicos. Para este trabalho, objetivou-se estudar uma proposta alternativa e eficiente para o acesso aos serviços de compartilhamento de bicicletas do projeto Bike Itaú, pois o uso deste veículo como meio de transporte deve ser considerado como algo positivo e relevante, tanto em termos de sustentabilidade, quanto em termos de saúde física e mental dos seus usuários.

Apesar da existência de três formas de desbloqueio das bicicletas do Bike Itaú, que são a ligação telefônica, o cartão e o aplicativo para smartphone, o serviço ainda carece de melhoria, no intuito de sanar ou ao menos amenizar os seus aspectos excludentes. Muitos usuários encontram-se, por vezes, em situação de não conseguir utilizar os serviços, seja pela falta de um telefone para realizar a ligação, por não terem cartão de desbloqueio ou, o mais comum, por possuírem smartphones antigos que não são compatíveis com as novas versões do aplicativo.

Entende-se que promover a inclusão social é resgatar os direitos dos cidadãos, promovendo assim uma sociedade justa e igualitária. Neste contexto, a proposta de melhoria aqui apresentada refere-se à implementação da tecnologia touchscreen nas estações de compartilhamento de bicicletas, de forma que a sua utilização permita que mais cidadãos tornem-se usuários. A escolha por esta tecnologia se deve, principalmente, a sua facilidade de uso, vindo a beneficiar todos os usuários, independentemente do seu nível de instrução ou faixa etária.

Conclui-se que o desenvolvimento de propostas que como esta buscam a inclusão social, a valorização da qualidade de vida e do meio ambiente devam ser recorrentes e incentivadas, fazendo parte da comunidade acadêmica e científica.
Realização:
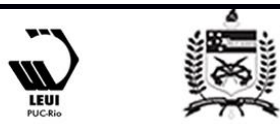


\section{Referências}

BA ECOBICI. 2016. Disponível em: http://www.buenosaires.gob.ar/aplicaciones moviles/ ba-ecobici. Acesso em 20 mai 2016.

BARRET, G.; OMOTE, R. Projected-Capacitive Touch Technology. Frontline Technology, p. 1621, 2010.

BAXTER, M. R. Projeto de Produto: Guia Prático para o Design de Novos Produtos. 2. ed. São Paulo: Edgar Blücher, 2005.

BIKE SALVADOR. 2016. Disponível em: http://www.bikesalvador.com. Acesso em 23 mai 2016.

BRASIL. Programa Gespública - Pesquisa de Avaliação da Satisfação: Guia Metodológico. Brasília, MP, SEGEP, 2013. Versão 1/2013.

BRASIL. Ministério das Cidades, Curso Gestão Integrada da Mobilidade Urbana. Módulo I: Política Nacional de Mobilidade Urbana. Ministério das Cidades, Programa Nacional de Capacitação das Cidades, Brasília, Março, 2006. Disponível em:

http://www.cidades.gov.br/CursoSemob/modulos.h tml. Acesso em 23 mai 2016.

CADENA, R.P.; ANDRADE, M.O.; BRASILEIRO, A. A necessidade da regulação do aluguel de bicicletas como serviço público complementar ao transporte urbano. Anais em meio eletrônico do XXVIII Congresso Nacional de Pesquisa e Ensino em Transportes. ANPET, Curitiba, 2014.

CITIBIKE. 2016. Disponível em: https://www.citibikenyc.com. Acesso em 20 mai 2016.

FERREIRA, A.C.M.; RAIA JR. Análise das taxas de mortalidade por atropelamento dos municípios paulistas utilizando ferramentas de estatística espacial. Revistas dos Transportes Públicos, p. 61-74, ano 32, $1^{\circ}$. quadrimestre de 2010. $16^{\circ}$ Ergodesign - Congresso Internacional de Ergonomia e Usabilidade de Interfaces Humano Tecnológica: Produto, Informações Ambientes Construídos e Transporte

$16^{\circ}$ USIHC - Congresso Internacional de Ergonomia e Usabilidade de Interfaces Humano Computador

CINAHPA | 2017 - Congresso Internacional de Ambientes Hipermídia para Aprendizagem.

FEIJÓ, B.V. Para a Serttel a ciclovia é o caminho do crescimento, 2015. Disponível em: http://exame.abril.com.br/revista-exame/no-ritmodas-bikes. Acesso em 18 out 2016.

GOMES, H.S. Brasil tem 5 milhões de celulares bloqueados por roubo ou perda, 2015.

Disponível em:

http://g1.globo.com/tecnologia/noticia/2015/02/bra sil-tem-5-milhoes-de-celulares-bloqueados-porroubo-ou-perda.html. Acesso em 05out 2016.

HAMMERSCHMIDT, R. O. O que é touchscreen? Tecmundo. 2008. Disponível em http://www.tecmundo.com.br/multitouch/177-oque-e-touch-screen-.htm. Acesso em 04 mai 2016.

MELBOURNE BIKE SHARE. 2016. Disponível em: http://www.melbournebikeshare.com.au/. Acesso em 20 mai 2016.

PEREIRA, J.A.G. Compartilhamento em alta no Brasil. Notas. 2014. Disponível em http://bibliotecadigital.fgv.br/ojs/index.php/pagina 22/article/download/27377/26247. Acesso em 20 mai 2016.

PMBOK. Um guia do conhecimento em gerenciamento de projetos. 5. Ed., São Paulo: ed. Saraiva, 2014.

RHENIUS, A.; MEIER, M. BASSO, M.V.A. O Sketchometry e a utilização de tecnologias Toutchscreen na Geometria Dinâmica. Nuevas ideas en informática educativa TISE. p.754-758, 2015.

SILVEIRA, M.O. Mobilidade Sustentável: A bicicleta como um meio de transporte integrado. 2010. 155p. Dissertação (Mestrado em Engenharia de Transportes), Universidade Federal do Rio de Janeiro, COPPE, Rio de Janeiro, 2010.

THE CITY FIX BRASIL. 2016. Disponível em: http://thecityfixbrasil.com. Acesso em 20 mai 2016.

VÉLIB. 2016. Disponível em: http://www.velib.paris. Acesso em 20 mai 2016
Realização:

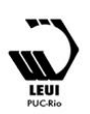

